\begin{tabular}{ccc}
\hline & International Journal of Engineering \& Technology, $7(2.12)(2018) 222-224$ \\
SPC & International Journal of Engineering \& Technology \\
Website: $w w w . s c i e n c e p u b c o . c o m / i n d e x . p h p / I J E T$ & Research Paper \\
\hline
\end{tabular}

\title{
Realization of trophy shaped flexible wearable antenna based on foam substrate
}

\author{
Reema Dubey ${ }^{1}$, Vinod Kumar Singh ${ }^{1}{ }^{*}$, Akash Kumar Bhoi ${ }^{3}$, Zakir Ali ${ }^{4}$ \\ ${ }^{1}$ SR Group of Institution, Jhansi, U.P. India \\ ${ }^{2}$ Sikkim Manipal Institute of Technology, Sikkim, India \\ ${ }^{3}$ I.E.T. Bundelkhand University, Jhansi, UP, India \\ *Corresponding author E-mail: singhvinod34@gmail.com
}

\begin{abstract}
The endeavor of this paper is to analyze a light weighted flexible antenna for modern communication system. There are three different patch designs with operating frequency $4 \mathrm{GHz}$. These proposed antennas are compact in size, shows high directivity and large bandwidth. Ex-pandable polystyrene foam is used as a substrate because such antenna are bendable, wearable, cheap, require less attention and having good features like low dielectric constant, low loss tangent and better efficiency. The antenna parameters like reflection coefficient, gain, band-width, radiation pattern are analyzed. The reflection coefficient of anticipated antenna provides a good concurrence between simulated and measured result. Foam based design is simulated by using CST studio.
\end{abstract}

Keywords: Expandable Polystyrene Foam; Copper Foil Tape; CST; Reflection; Coefficient.

\section{Introduction}

In last year's, the demand of flexible antenna has been increased tremendously. A major factor in area of demanding of such antenna is the advancement in computer architecture and numerical computation [1-4]. Microstrip patch antenna offers wide applications in satellite communication, telecommunication, navigation system etc. [5-9]. The choice of substrate gives antenna performance in terms of impedance bandwidth, gain, radiation pattern. For flexible and wearable applications there are many dielectric material like paper, expandable polystyrene foam (EPS), leather etc. available in market. These materials are light in weight, low cost profile, less relative permittivity. The proposed antenna design is used foam as a substrate whose relative permittivity $\varepsilon_{r}=1$ that is approximately equal to air dielectric constant. Due to this losses and attenuation are very less than other substrate antenna [10-12]. It enhances the bandwidth of antenna.

In proposed antenna foam is used as a substrate material sandwiched between two layers of copper tape of width 0.038 . First layer is ground and other layer is patch shape. Here height $\mathrm{h}$ of substrate is $2 \mathrm{~mm}$, dielectric constant is 1 and operating frequency is 4 GHz. In this paper simulation is done by using CST software studio and gives the results in terms of reflection coefficient, gain, bandwidth and efficiency [13-15].

\section{Design of antenna}

Fig.1 illustrates Trophy shape antenna consist three layers in which first layer is known as ground, made by copper tape of $0.03 \mathrm{~mm}$ thickness, second layer is of substrate. In this paper foam of $2 \mathrm{~mm}$ height is using as a substrate. Patch design is made by using copper tape on substrate. Probe connection is provided in microstrip feed line. This method is very easy to fabricate and commonly used for

power feeding. This antenna is fully ground by using copper conducting material. The specifications are shown below in table 1 .

(A)
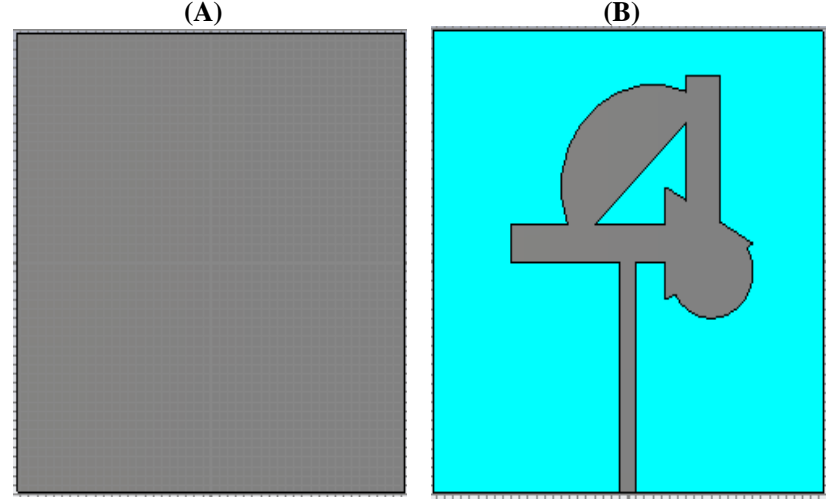

Fig. 1: Proposed Antenna Geometry (A) Back Side (B) Front Side.

Table 1.1: Design Specifications of Proposed Antenna

\begin{tabular}{lll}
\hline S. No. & Antenna Parameter & Values \\
\hline 1. & Relative permittivity $\left(\varepsilon_{\mathrm{r}}\right)$ & 1 \\
2. & Substrate height & $2 \mathrm{~mm}$ \\
3. & Loss tangent & 0.025 \\
4. & Ground dimension & $46 \mathrm{~mm} \times 49 \mathrm{~mm}$ \\
5. & Substrate dimension & $46 \mathrm{~mm} \times 49 \mathrm{~mm}$ \\
6. & Microstrip feed line dimension & $22 \mathrm{~mm} \times 2 \mathrm{~mm}$ \\
7. & Operating frequency & $4 \mathrm{GHz}$ \\
\hline
\end{tabular}

\section{Simulated results}

Simulation of anticipated antenna is done by CST software. Fig. 2 shows the reflection coefficient plot of anticipated antenna3. The presented antenna provides the wideband of $47.20 \%(9.84 \mathrm{GHz}-$ 
$15.92 \mathrm{GHz}$ ) at resonance frequency $10.10 \mathrm{GHz}$ and $15.35 \mathrm{GHz}$. Simulated results of polar plot of proposed antenna are publicized in Fig.3. Fig.4 shows 3D pattern of presented antenna at $10.1 \mathrm{GHz}$ and $15.35 \mathrm{GHz}$. This presented antenna has good directivity $7.765 \mathrm{dBi}$ at $10.1 \mathrm{GHz}$ and $8.524 \mathrm{dBi}$ at $15.35 \mathrm{GHz}$.

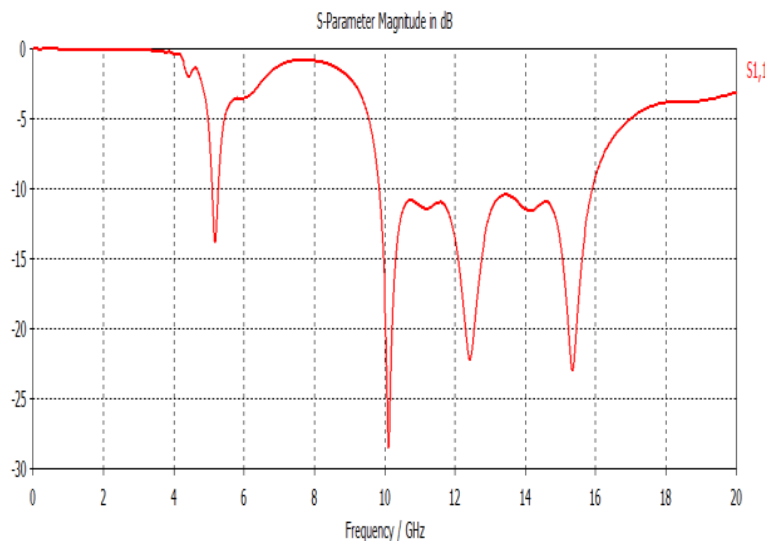

Fig. 2: Simulation Return Loss vs. Frequency Plot of Proposed Antenna3.

Directivity Abs (Phi=90)

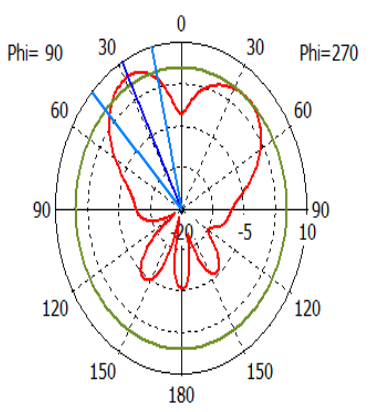

Theta / Degree vs. dBi

farfield $(f=10.1)[1]$

Frequency $=10.1$

Main lobe magnitude $=6.9 \mathrm{~dB}$

Main lobe direction $=28.0$ deg. Angular width $(3 \mathrm{~dB})=31.8 \mathrm{deg}$. Side lobe level $=-1.6 \mathrm{~dB}$

Directivity Abs (Phi=90)

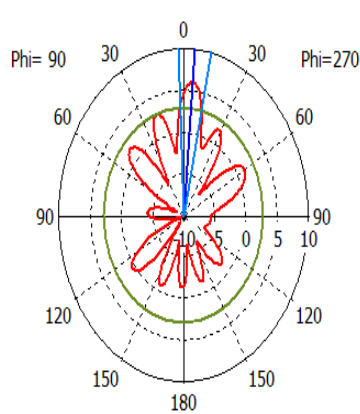

Theta / Degree vs. dBi
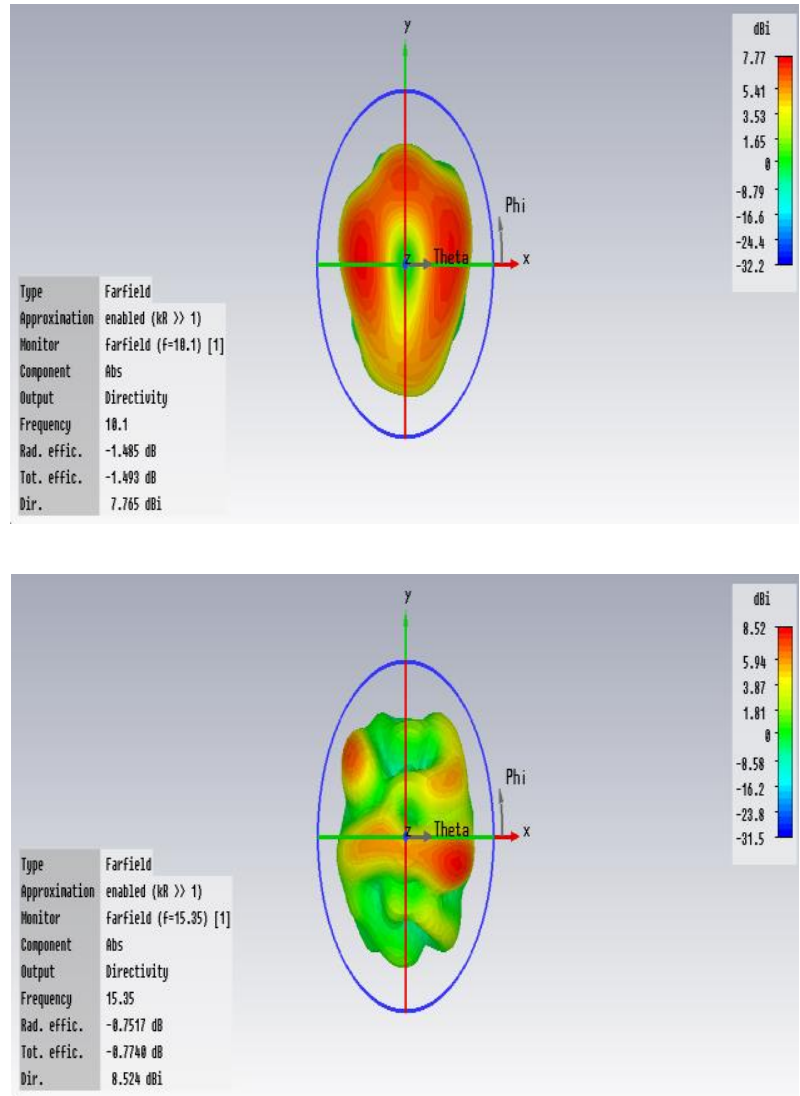

Fig.4: 3D Pattern of Presented Antenna at $10.1 \mathrm{GHz}$ and $15.35 \mathrm{GHz}$.

\section{Evaluation steps of proposed antenna}

This section presents different steps of proposed antenna and comparative simulated return loss which is shown in Fig.5 and Fig.6. The reflection coefficient $\&$ bandwidth of anticipated antenna 3 are better than antenna1 and antenna2. The comparative study of presented antennas gives the larger bandwidth with high directivity which is need of directional antenna.
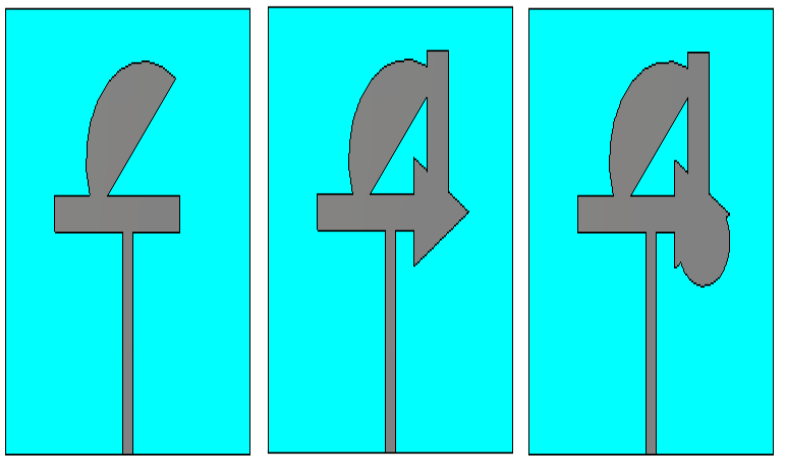

Fig. 5: Geometry of the Proposed Antennas (A) Antenna1 (B) Antenna2 (C) Antenna3 


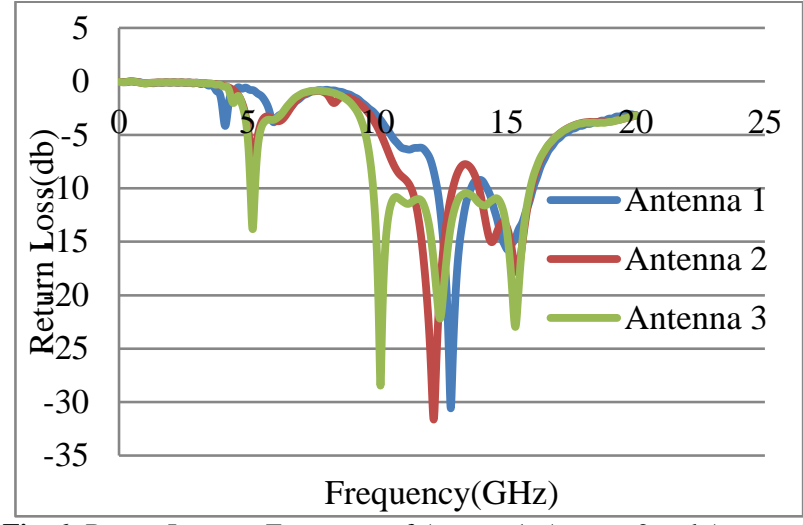

Fig. 6: Return Loss vs. Frequency of Antenna1, Antenna2 and Antenna3.

\section{Fabricated antenna and experimental re- sults}

The hardware of designed antenna is shown in fig.7. This hardware describes foam as a substrate and copper as conductive patch. The fabricated antenna is tested in Microwave lab at IIT Kanpur. The simulated and measured results are shown in fig. 1.8. There is a small variation in simulated and measured return loss curve due to uncertainties in dielectric constant, soldering effects and quality of probe.
(A)

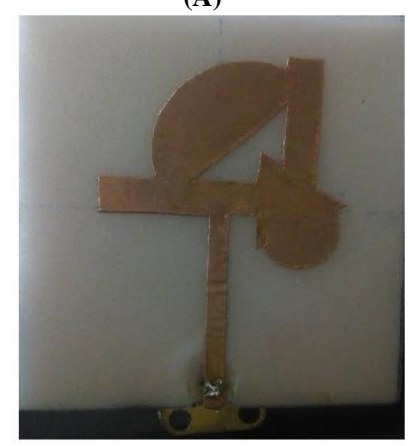

(B)

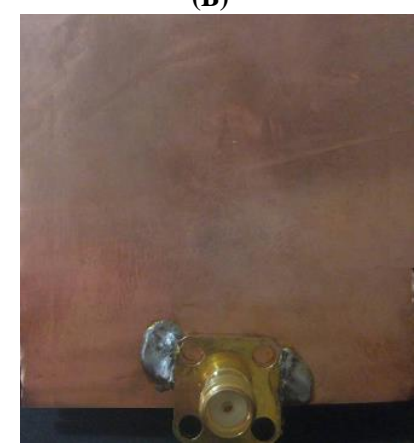

Fig. 7: Hardware of Anticipated Antenna 3 (A) Front Side (B) Back Side.

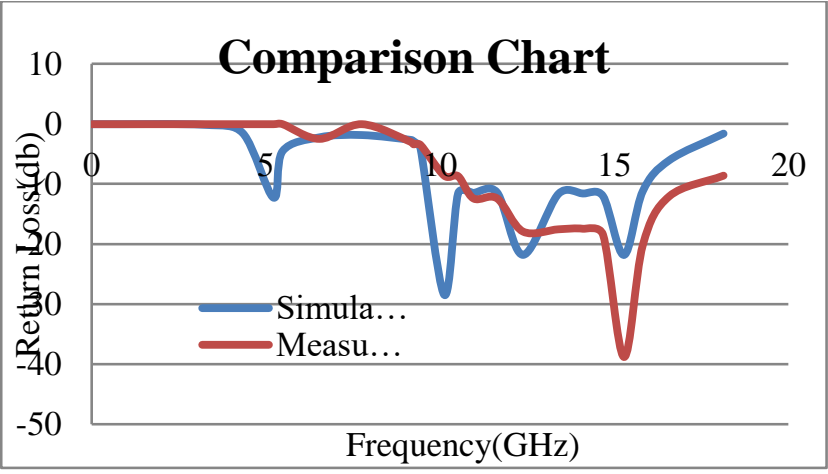

Fig. 8: Similarity of Simulated and Measured Return Loss Plot of Proposed Antenna3.

\section{Conclusion}

The designed foam based flexible antenna can be used for modern communication systems. There are wide applications in body worn system, satellite communication and wireless communication. A designed antenna is small in size and provides good results according to our requirements. It gives high directivity, wide bandwidth. The main purpose of using foam as a substrate is its dielectric constant value which is approximately equal to 1 so that minimum losses occur. Designed antenna covers bandwidth $40.81 \%$ $(10.96 \mathrm{GHz}-16.58 \mathrm{GHz})$ and gives high directivity of $8.524 \mathrm{dBi}$.

\section{Acknowledgement}

The authors would like to thank Dr. Kumar Vaibhav Srivastav, IIT Kanpur, UP, India to provide the facility for the antenna measurements at IIT Kanpur Microwave Lab.

\section{References}

[1] Balanis C. A, Antenna Theory: Analysis and Design, John Wiley and Sons, New York, 2004

[2] Vinod Kumar Singh, and B. Naresh,: Multi Resonant Microstrip Antenna with Partial Ground for Radar Application, Journal of Telecommunication, Switching Systems and Networks, vol. 2, no. 1, pp. 01-05, (2015).

[3] Manvendra Singh, Vinod Kumar Singh, and B. Naresh: Rectangular Slot Loaded Circular Patch Antenna for WLAN Application, JTSSN, vol. 2, no. 1, pp. 07-10, (2015).

[4] Vinod Kumar Singh, and Nikhil Kumar Singh,: Compact Circular Slotted Microstrip Antenna for Wireless Communication Systems, JOMET vol. 1, no. 1, pp. 07-14, (2015).

[5] Vinod Kumar Singh, Zakir Ali, Shahanaz Ayub, and Ashutosh Kumar Singh,: Bandwidth Optimization of Compact Microstrip Antenna for PCS/DCS/Bluetooth Application, CEJE, Springer, vol. 4 no. 3, pp. 281-286, (2014)

[6] Nikhil Singh, Ashutosh Kumar Singh, and Vinod Kumar Singh,: Design and Performance of Wearable Ultra Wide Band Textile Antenna for Medical Applications, MOTL, vol. 57, no. 7, pp-1553-1557, (2015).

[7] Nikhil Kumar Singh, Vinod Kumar Singh, and Naresh. B,: Textile Antenna for Microwave Wireless Power Transmission, Procedia Computer Science, vol. 85, pp. 856 - 861, (2016).

[8] Neha Gupta, Vinod Kumar Singh, Zakir Ali, and Jitendra Ahirwar, Stacked Textile Antenna for Multi Band Application Using Foam Substrate, Procedia Computer Science, vol. 85, pp. 871- 877, (2016).

[9] Amit Kumar Rawat, Vinod Kumar Singh, and Shahanaz Ayub, Compact Wide band Microstrip Antenna for GPS/WLAN/WiMax Applications, International Journal of Emerging Trends in Engineering and Development, no. 2 vol. 7, pp. 140 -145, (2012).

[10] Rishabh Kumar Baudh, Ranjan Kumar, and Vinod Kumar Singh, Arrow Shape Microstrip Patch Antenna for WiMax Application, Journal of Environmental Science, Computer Science and Engineering \& Technology, vol. 3, no.1, pp. 269-274, (2013).

[11] Naresh B., Vinod Kumar Singh, " $4.65 \mathrm{GHz}$ Wearable Rectenna for low power Wireless applications", International Conference on Electrical, Computer and Communication Technologies, Department of Electrical and Electronics Engineering, SVS College of Engineering, Coimbatore, Tamil Nadu, 2017.

[12] Naresh B., Singh V.K., Bhargavi V. Low Power Circularly Polarized Wearable Rectenna for RF Energy Harvesting, Lecture Notes in Electrical Engineering, vol 436, pp. 131-138, Springer, Singapore.

[13] Naresh B., Singh V.K., Bhargavi V., Garg A., Bhoi A.K. Dual-Band Wearable Rectenna for Low-Power RF Energy Harvesting, Lecture Notes in Electrical Engineering, vol 436 pp. 13-21. Springer, Singapore.

[14] Rajat Srivastava, Shahanaz Ayub, and V. K. Singh,: Dual Band Rectangular and Circular Slot Loaded Microstrip Antenna for WLAN/GPS/WiMax Applications, International Conference on Communication Systems and Network Technologies, pp. 45 - 48, (2014).

[15] Naresh B., Vinod Kumar Singh, "Dual band RF Energy Harvester for Wearable Electronic Technology", $3^{\text {rd }}$ International Conference on Advances in Electrical, Electronics, Information, Communication and Bio-Informatics, 2017. 